Autism (2018)

THE PREVALENCE OF AUTISTIC TRAITS IN A HOMELESS POPULATION

Alasdair Churchard, Morag Ryder, Andrew Greenhill, William Mandy

ABSTRACT

Anecdotal evidence suggests that autistic people experience an elevated risk of homelessness, but systematic empirical research on this topic is lacking. As a step towards filling this gap in knowledge, we conducted a preliminary investigation of the prevalence of DSM-5 autism symptoms in a group of long-term homeless people. The entire caseload ( $N=106)$ of a UK homeless outreach team was screened (excluding individuals born outside of the UK or Republic of Ireland) using an in-depth, semi-structured interview with keyworkers, based on DSM-5 diagnostic criteria. This showed adequate inter-rater reliability, as well as evidence of criterion and construct validity. Of the sample, 13 people $(12.3 \%, 95 \% \mathrm{Cl}[7.0,20.4])$ screened positive, meeting DSM-5 autism criteria by keyworker report. A further nine people $(8.5 \%, 95 \% \mathrm{Cl}[4.5$, 15.3]) were 'marginal', having autistic traits that were not quite sufficient to meet DSM-5 criteria. Those with elevated autistic traits, compared to those without, tended to be more socially isolated, and less likely to use substances. This study has provided initial evidence that autistic traits are over-represented among homeless people; and that autistic homeless people may show a distinct pattern of characteristics and needs. Further investigation is required to build upon these provisional findings.

Keywords: autism; homelessness; adults 
Autism (2018)

\section{THE PREVALENCE OF AUTISTIC TRAITS IN A HOMELESS POPULATION}

Autism is a neurodevelopmental condition characterised by difficulties with social relating, social communication, flexibility and sensory processing (American Psychiatric Association [APA], $2013)^{1}$. It occurs in approximately one percent of the population, and persists across the lifespan (Brugha et al., 2016). Autism is a dimensional condition, representing one end of a continuum of traits that extends throughout the general population (Robinson et al., 2017). A realistic understanding of autism should not only focus on the difficulties arising from the condition, but must also include consideration of the strengths of autistic people. For example, the majority of autistic people diagnosed according to current conventions have fluent language and an IQ in the normal range (Loomes et al., 2017; Centres for Disease Control, 2014). Furthermore, many have capacities that stem directly from their autism (e.g., Howlin et al., 2009; Meilleur, Jelenic \& Mottron, 2015; Soulières, Dawson, Gernsbacher \& Mottrom, 2011).

Despite their autism-related strengths, and the fact that many autistic people lead satisfying adult lives, under current systems of care people on the autism spectrum are at high risk of poor adult outcomes (Howlin \& Moss, 2012). These include social isolation, educational and occupational under-attainment, difficulty establishing independent living, poor quality of life and increased risk of an early death (Brugha et al., 2011; Howlin \& Moss, 2012; van Heijst \& Guerts, 2015; Schendel et al., 2016). In the current study we seek to investigate the link between autism and a different adult outcome, namely homelessness. This has received very limited attention in the empirical literature to date, and may well represent an important part of the picture of adult outcomes of autistic people.

\footnotetext{
${ }^{1}$ In this paper, we use the term 'autism' as a direct synonym for the DSM- 5 diagnostic entity of 'autism spectrum disorder' (ASD). We have chosen not to use the term ASD, as we do not accept the assumption it conveys, that autism is inherently a state of mental disorder.
} 
Autism (2018)

Homelessness is an umbrella term which covers a range of different situations. It refers to rough sleepers, that is people who sleep or bed down in the open air, or in buildings or other places not intended for human habitation (Crisis, 2017). It also includes people who do sleep in a place designed for habitation, but who do not have any legal title to their accommodation or access to any private spaces for their social relations (Fazel et al., 2014). Homelessness both arises from and contributes to vulnerability: it has severe negative effects on physical and mental health (Fazel et al., 2014). If autistic people are more likely to become homeless, it is important to document this so that a potential subset of the homeless population can be identified and appropriate resources extended to them. This would also help with the development of targeted measures to help prevent autistic people becoming homeless in the first place.

The current study aims to explore the relationship between autism and homelessness, by making an initial estimate of the prevalence of autistic traits in a homeless population. This work was initially motivated by anecdotal reports from autism clinicians and keyworkers in a homeless support service that rates of autism may be elevated in this population (e.g., Homeless Link, 2015). In line with this, there is indirect empirical evidence to support the idea that autism is a risk factor for homelessness. Autistic adults, compared to those without autism, experience elevated rates of mental health problems, greater difficulties attaining independent living conditions, lower educational and occupational attainment, and a higher risk of social isolation (e.g., Howlin \& Moss, 2012; Magiati, Tay \& Howlin, 2014). All of these characteristics are known risk factors for homelessness (Fazel et al., 2008, 2014).

We know of no studies published in peer-reviewed journals testing directly whether autism predisposes people to homelessness. However, there are two studies in the 'grey literature' (i.e., not published in peer-reviewed academic journals) that support this idea. In one small- 
Autism (2018)

scale internal audit in a UK National Health Service setting, a psychiatrist investigated the presence of autism in a group of 14 homeless men with social difficulties (NHS Devon, 2011). Seven members of this preselected group were judged to have shown strong signs of autism, based on a non-standardized but thorough assessment involving interviews with 12 of the 14 homeless individuals, interviews with workers, and also reviewing case notes. In another study, the National Autistic Society in Wales surveyed 415 autistic adults and family members of people with autism. Twelve percent of these autistic adults reported having been homeless at least once since leaving school (Evans, 2011). These findings are based on suboptimal methods of sampling and measurement and have not been subjected to peer review, and so must be treated cautiously. Nevertheless, they suggest the value of a more systematic investigation of the link between autism and homelessness.

The task of assessing rates of autism in a homeless population is difficult. Diagnosing autism in adults is in itself challenging (Lai and Baron-Cohen, 2015), and homelessness complicates assessment further. The ideal process of assessing autism in adults involves combining the results from standardised self-report, direct observation and informant report measures to gain a picture of current behaviour and developmental history (NICE, 2012). This intensive process requires a high degree of engagement from the person being assessed, and from someone who knew them as a child. Difficulties with engagement are ubiquitous in work with homeless people (Kryda and Compton, 2009; Olivet et al., 2010) and gaining any kind of history can be extremely difficult in this group, as they have often lost contact with family and friends (Roll, Toro, and Ortola, 1999). Other factors such as high rates of substance misuse, mental health problems, and a disjointed social environment all also complicate the process of assessment (Fazel et al., 2014). Furthermore, there are no autism measures that have been validated for use with homeless people (Sappok, Heinrich, and Underwood, 2015). 
Autism (2018)

Reflecting the challenges of assessing autism in homeless people, our work has the following features. First, we directly acknowledge that we are unable to offer definitive diagnoses of autism in the current study. Instead we seek to derive an initial estimate of autistic traits, including those of sufficient quality and quantity to be suggestive of a DSM-5 diagnosis. Second, instead of using self-report and/or direct observation, we chose to measure autistic traits by informant report, with the informants being keyworkers in a homeless support service. These are staff members who work directly with homeless adults to help them make positive changes, and also coordinate their contact with diverse services. In this role keyworkers work with their homeless clients over a sustained period of time and generally know them well. Our decision to use informant report was in response to the likelihood that a large proportion of the homeless population we sampled would not engage with research. Those with autistic social communication difficulties would likely be among the least likely to participate, which would introduce a bias into any estimate of prevalence. A similar informant-report approach was adopted by Fraser and colleagues (2012) with another hard-to-engage population, when they estimated autism prevalence amongst patients in youth mental health services by interviewing their key clinicians. Whilst we acknowledge that this approach does not offer a gold-standard autism assessment, it does allow us to investigate the full caseload of a homeless service, thereby limiting sampling bias.

A third key feature of this study is that, given the lack of relevant measures validated for homeless people, we collected data using an in-depth interview, structured according to the DSM-5 description of autism spectrum disorder. Any measure should possess reliability and validity (Streiner, Norman \& Cairney, 2015). We assessed the inter-rater reliability by blind double-coding a random selection of interviews. Criterion validity is the extent to which a measure co-varies with another measure of the same construct. In this study, we administered 
Autism (2018)

the most appropriate extant autism measure for keyworker assessment of autistic traits, the Autism Spectrum Disorder in Adults Screening Questionnaire (Nylander \& Gillberg, 2001); and checked how this correlated with outcomes from our semi-structured DSM-5 interview.

Construct validity is the extent to which an instrument shows the pattern of association with other measures that would be predicted based on what we know about the construct being measured (Barker \& Pistrang, 2015). We made three a priori construct validity hypotheses. First, since autism is associated with higher risk of social isolation (Gray et al., 2014), we predicted that if the interview possesses validity, those with high autism trait scores should show elevated levels of social isolation. Second, we predicted that high autism trait scores would be associated with lower levels of substance abuse in the homeless population. This was based on reports from homelessness experts we consulted that, compared to the non-autistic homeless population, their autistic homeless clients are less likely to abuse substances. In support of this is the meta-analytic finding that rates of drug dependence $(24.4 \%, 95 \% \mathrm{Cl}[13.2-35.6])$ and alcohol dependence $(37.9 \%, 95 \% \mathrm{Cl}[27.8,48.0])$ are very high in the general homeless population (Fazel et al., 2008). By contrast, such problems are much less common amongst autistic adults, as shown by a recent whole-population study that found $3.4 \%$ of their autistic participants had substance-use related problems (Butwicka et al, 2017). Our third construct validity hypothesis concerned non-autistic psychopathology. Mental health problems are very common amongst homeless people, and such difficulties could artificially inflate scores on any measure of autistic traits. For example, if a person is socially withdrawn due to psychosis or social anxiety, this could mistakenly be taken as a symptom of autistic social impairment. Therefore, we reasoned that if our instrument has construct validity, it will not be strongly associated with non-autistic mental health difficulties in the homeless population. 
Autism (2018)

In summary, our overall aim is to derive an initial estimate of the prevalence of autistic traits in a homeless population using informant reports. To this end we sought to address the following questions:

1. Does the DSM-5 keyworker interview that we used to evaluate autistic traits show interrater reliability?

2. Does the DSM-5 interview show criterion validity, as indicated by agreement with another professional-report measure of autistic traits?

3. Does the DSM-5 keyworker interview show construct validity, as indicated by those with higher autistic trait scores, compared to those with lower autistic trait scores, being more socially isolated, less likely to abuse substances, and having equivalent levels of mental health difficulties?

4. What proportion of the caseload of a long-term homeless service have elevated levels of informant-reported autistic traits, consistent with a DSM-5 diagnosis of autism?

\section{METHODS \\ Procedure}

The study was based in a homelessness outreach team in an urban area in the UK. In this team, each homeless person has a keyworker, a member of staff who coordinates their contact with services and works directly with them over a sustained period of time. At the start of this project, the research team provided an autism training workshop for the keyworkers to improve the quality of reporting; to reduce biases that could arise from variations in keyworkers' autism knowledge; and to engage the keyworkers in the project. This training workshop included a presentation and structured case discussion facilitated by the research team, and lasted two and a half hours. Subsequently, all keyworkers agreed to participate. This involved them completing a separate interview for each of their homeless clients. The only homeless clients who were not 
Autism (2018)

the focus of an interview were those born outside of the UK and the Republic of Ireland. We suspect that homelessness for those born outside the UK and Ireland, including refugees, is a distinct phenomenon, in terms of its causes and characteristics (Fitzpatrick, Johnsen, and Bramley, 2012; Phillips, 2006).

This study received ethical approval from the University College London Research Ethics Committee, reference 8359/001. All keyworkers were provided with an information sheet and consent form. We followed procedures to protect the privacy and confidentiality of the homeless people who were the focus of the research interviews. The homeless people were not identifiable to the research team: we were not told names or any other identifying information such as date of birth.

The joint first authors conducted the interviews. At the time of the research they were clinical psychology trainees working as psychologists in the UK National Health Service and studying for their doctorate in clinical psychology. This role involves extensive general training on assessment, and they also received specialist training in autism from the third and fourth authors (both experienced in the diagnosis of autism), which included feedback on pilot interviews they had carried out.

\section{Participants}

Nine keyworkers took part in the study, of whom six were female. Keyworkers were aged between 36 and 57 years old (average age $=42.6$ years, $S D=6.4$ ). The amount of time they had worked in homelessness services ranged from 6-26 years (average $=15.0$ years, SD $=7.3$ ). The amount of time they had worked in their current role ranged from 2.5-8 years, with the average being 3.8 years $(S D=2.0)$. Keyworkers had, on average, $11.8(S D=4.5)$ cases each. The amount of time clients had been known by their keyworkers ranged from 0-19 years, with the average 
Autism (2018)

being 2.9 years $(S D=3.5)$. The majority of the sample $(54.1 \%)$ were seen by keyworkers at a minimum of once a fortnight, $10.2 \%$ were seen monthly, and contact was variable or intermittent in $34.7 \%$ of cases.

Of 137 homeless people on the caseload, 106 were born in the UK or Republic of Ireland and so were the focus of an interview. Of these, $91(85.8 \%)$ were male. Their average age was 48.9 years $(S D=12.7)$, and $87.7 \%$ were White British. The average length of homelessness was 11.7 years $(S D=8.5)$. The most common accommodation situations were as follows: $46(43.4 \%)$ were street homeless; 20 (18.9\%) were in a homeless hostel; 10 (9.4\%) were in independent accommodation (e.g., their own accommodation to which they had legal title); 10 (9.4\%) were in semi-independent accommodation (e.g., accommodation they had legal title to, but where a condition of having the accommodation was that they engaged with specified support); and 9 (8.5\%) were in prison. The remaining $11(10.4 \%)$ were either in emergency accommodation, with friends and family, had disappeared for more than 90 days, or had their accommodation situation listed as 'other'. Sixty-three (59.4\%) were known to use drugs and/or alcohol, and 34 (32.1\%) had an officially diagnosed mental health condition, although a much higher number were suspected of having a mental health condition.

\section{Measures}

DSM-5 based semi-structured interview

We used keyworkers' knowledge of their clients to identify those homeless individuals with observable traits of autism. To do this we created a 'DSM-5 Autistic Traits in the Homeless Interview', which we call the 'DATHI'. This allowed us to gather in-depth information about the individual's presentation. The DATHI was developed through the following sequential process: 1) consultation with experts on homelessness, including those with experience of working with autistic homeless people; 2) going through the DSM-5 criteria in detail and creating a draft 
Autism (2018)

interview; 3) consultation on this draft with the local Adult Autism Special Interest Group, which comprises clinicians from several local adult autism assessment services; 4) Piloting the measure with keyworkers from the homeless outreach team. At each stage the interview was adapted based on feedback received.

The DATHI, which is presented in the online supplementary materials for this article, was based on DSM-5 criteria for autism spectrum disorder. It has separate sections for each of the seven criteria, with general questions followed by specific prompts. For example, a question about eye contact (part of DSM-5 criterion A2) was followed by prompts about whether eye contact was absent, or whether the individual had a fixed gaze. Some questions were adapted to the homelessness context, based on the information gained from experts in the development phase. An example of this was that one prompt in the section based on DSM- 5 criterion B2 asks about ritualised behaviour in relation to sleep sites. The focus here was on whether there were especially fixed patterns of sleep site selection, or if the person set up their sleep site in a ritualistic fashion.

The DATHI was scored by rating whether autism symptoms were present for each of the seven DSM-5 criteria. A range of scoring options were used to ensure that a criterion was only classified as 'Present' if there was good evidence that this was the case, as we expected that there would be a wide variety in presentations and it would be difficult in some cases to decide whether or not a particular behaviour was a characteristic of autism. The other potential scoring options were: 'Possibly present', 'Not present', 'Present but attributable to cause other than autism', and 'Insufficient information to classify'.

Scores on individual criteria were combined to make an estimated overall classification for each homeless person. There were four possible summary outcomes: (1) screened positive - high 
Autism (2018)

likelihood of DSM-5 autism; (2) marginal - medium likelihood of DSM-5 autism; (3) screened negative - low likelihood of DSM-5 autism; (4) unclassified - insufficient information. The rules to assign each of these summary outcomes are shown in Table 1.

[Table 1 here]

\section{Autism Spectrum Disorder in Adults Screening Questionnaire (ASDASQ)}

The ASDASQ is an informant-report autism screening measure, developed for mental health clinicians to rate autistic symptoms of their patients (Nylander and Gillberg, 2001). This asks questions about the person's current presentation, with answers in a yes/no format. Potential scores range from 0-9, with higher scores indicating a higher probability of being autistic. Given the prevalence of mental health conditions among homeless people (Fazel et al., 2008) and the fact that it is designed to be completed by professionals, we considered that the ASDASQ was the most suitable instrument to use in the current study, in order to explore the criterion validity of the DATHI.

\section{Additional information gathered to test construct validity}

Information on mental health and substance use was gathered via a structured questionnaire completed by keyworkers drawing upon client's notes. A score of 1 was given for mental health diagnoses if clients had one of more formal diagnoses. Substance use was coded separately where a score of 1 was given for the use of alcohol or any illegal drug of any amount taken weekly to monthly. An additional semi-structured interview was used with keyworkers to gather observable information about their clients' social contacts. These qualitative data were then quantitatively coded using content analysis (Elo \& Kyngäs, 2008), with respect to four main categories of relationships (partner, family, peer relationships or socially isolated). A code of 1 was given for each category if there was evidence of a current partner, any peer relationship 
Autism (2018)

including 'drinking buddies' or acquaintances known through drug taking and any contact with any family including by text or phone. If a person scored 0 on all 3 categories they were given a score of 1 in the totally isolated category. For this coding process, inter-rater reliability was calculated based on a second rater (AC) blind coding twenty interviews, which had originally been coded by MR. This showed high level of agreement across the categories; partner $(k=1, p$ $<.0001, \mathrm{Cl}: 1,2)$, peer relationships $(\mathrm{k}=0.9, \mathrm{p}<.0001, \mathrm{Cl}: 0.72,1.62)$ and family contact: $(\mathrm{k}=$ $0.73, \mathrm{p}=.001, \mathrm{Cl}: 0.4,1.13)$. We also gathered information about whether any individuals had pre-existing diagnoses of either autism or intellectual disability.

\section{Data analysis}

Reliability checking and assigning final classification

After classifications were made by the primary researchers (AC and MR) the reliability of the DATHI was investigated. This was done by selecting all the 'screened positive' and 'marginal' cases $(n=22)$ and a random selection of cases that had 'screened negative' $(n=16)$. The decision to over-select positive and marginal cases, rather than take a random selection from all cases screened, was made to provide a more rigorous test of the reliability of the measure.

All written information collected in the assessment was shared with the raters who were blind to scores assigned in the DATHI, and to the final classification. Reliability was checked for each of the seven DSM-5 criteria and for the overall classification made, using Fleiss's kappa (Fleiss and Cohen, 1973). By convention kappa values below .20 indicate limited reliability, .41 to .60 'moderate' agreement, .61 to .80 'substantial' agreement and .80 to 1 'very strong' agreement (Landis \& Koch, 1977). The reliability raters (the third and fourth authors) are experienced in assessing autism in adults in both clinical practice and research. 
Autism (2018)

After reliability checking was complete, a consensus decision was made by the whole research team about classification for those cases where there was a disagreement between the original classification and that made by the reliability rater.

Examining criterion validity

In addition to generating an overall classification for each individual, classifications for individual DSM-5 criteria were converted into numerical scores. If an item on the DATHI screened positive (classified as 'Present') it was given a score of 2; if it screened marginal (classified as 'Possibly present') it was given a score of 1; if it screened negative (classified as 'Not present', 'Present but attributable to cause other than autism', or 'Insufficient information to classify') it was given a score of 0 . These scores were then summed to provide an overall DATHI score, as well as subscale scores for DSM-5 Criterion A (social communication / social reciprocity) and Criterion B (restrictive, repetitive patterns of behaviour). Correlations between these DATHI scores and the ASDASQ were calculated to examine criterion validity.

Examining construct validity

The construct validity of the DATHI was examined by comparing those identified as having elevated autistic traits (i.e., people screening positive or marginal on the DATHI overall) with those without elevated autistic traits on the following variables reported by keyworkers: (1) substance misuse; (2) mental health diagnoses; (3) social connectedness. Group differences for these categorical outcomes were expressed as odds ratios with $95 \%$ confidence intervals.

All analyses were conducted using IBM SPSS Statistics version 24. Fleiss's kappa was calculated using a plug-in for SPSS downloaded from the IBM developerWorks website (IBM SPSS, 2015).

RESULTS 
Autism (2018)

Figure 1 shows the process of carrying out interviews and classification. It has details of total numbers screened, how many did not meet inclusion criteria, and when reliability checks were carried out and final classifications made. Interviews with keyworkers took 20-60 minutes per case, as more complex cases required more follow up questions on the DATHI.

\section{[Figure 1 here]}

\section{Reliability of the DATHI}

Inter-rater reliability coefficients are shown for each DSM-5 criterion on the DATHI in Table 2. According to widely used guidelines for interpreting kappa (Landis and Koch, 1977), inter-rater reliability for criterion $\mathrm{A} 1$ (socio-emotional reciprocity) is in the 'moderate' range, whilst for the other six DATHI items it is 'substantial'. We also looked at inter-rater agreement for overall classification, in terms of whether or not the DATHI identified an individual as screening positive. Fleiss's kappa was $0.69,95 \% \mathrm{Cl}[0.37,1.0], \mathrm{p}<.001$, indicating a substantial level of agreement between raters on this outcome (Landis and Koch, 1977).

[Table 2 here]

\section{Criterion validity of the DATHI}

The overall score from the DATHI was significantly and substantially correlated with the ASDASQ $(r=.81, p=.01)$. The ASDASQ was also significantly correlated with the DATHI scores for DSM-5 Criterion A (social communication and social reciprocity, $r=.71, p=.01$ ) and for Criterion $\mathrm{B}$ (restrictive and repetitive behaviours, $r=.81, p=.01$ ).

Informant reported autistic traits in a homeless population 
Autism (2018)

Table 2 shows the proportion of homeless people reported to show difficulties consistent with each DSM-5 autism criterion. The full range of answer codes for DATHI items were used, but the 'Attributable to other causes' code was applied for only two homeless individuals where either use of alcohol or a psychotic episode led to a very brief and obvious shift in the individual's presentation. Table 3 gives examples of keyworker observations that led to individuals scoring positive for specific DATHI items. In some instances superficial details in this table have been altered to maintain the confidentiality of clients.

[Table 3 here]

Item-level DATHI scores were used to make overall classifications according to the a priori algorithm described in Table 1. After the final classification 13 of the 106 cases screened positive, showing sufficient keyworker-reported autistic symptoms to meet DSM-5 criteria. This equates to a prevalence in this population of $12.3 \%, 95 \% \mathrm{Cl}[7.0 \%, 20.4 \%]$. Nine cases were identified as showing marginal evidence of DSM-5 autism, 72 as not showing any evidence of autism, and 12 as being insufficiently well known to services to be given a classification. Table 4 gives basic demographic details and length of homelessness for each classification. Supplementary Table S1 shows the profile of autistic symptoms on the DATHI for each individual who screened positive or marginal for autism traits.

[Table 4 here]

Characteristics of high and low autism traits scorers - construct validity of the DATHI As is shown in Table 5, in line with our construct validity predictions, homeless people who were identified by the DATHI as having elevated autistic traits (i.e., who screened positive or marginal) were more socially isolated than low trait scorers. They were less likely to have a reported 
Autism (2018)

substance abuse problem. Autistic traits on the DATHI were not associated with having a nonautistic mental health diagnosis. With regards to intellectual disability (ID), four people out of the total sample were known to have ID diagnoses. One of these screened positive on the DATHI, three screened negative. One individual was reported as having a pre-existing diagnosis of autism, and this person screened positive on the DATHI.

[Table 5 here]

\section{DISCUSSION}

We sought to investigate a possible link between autism and homelessness, by gathering initial evidence as to the prevalence of autistic traits in homeless people. We developed an interview to be administered to keyworkers, based on DSM-5 diagnostic criteria, and used this to screen the entire caseload of a homelessness service in a large English city. There was evidence in support of the reliability and validity of the DSM-5 interview we developed. According to reports of keyworkers, $12.3 \%$ of homeless people had a range of autistic traits consistent with meeting DSM-5 diagnostic criteria. This is substantially higher than the general population autism prevalence of 1\% (Brugha et al., 2016). Rates of autism may therefore be raised in this homeless population, and further investigation is warranted to understand links between autism and homelessness.

\section{Reliability and validity of DATHI}

To our knowledge, there is no prior research in peer-reviewed journals on autism and homelessness. This likely, in part, reflects the considerable challenges of assessing autism in homeless adults. Many homeless people are reluctant to engage with professionals, reports from relatives are often impossible to attain, presentations are complicated by co-occurring 
Autism (2018)

difficulties (e.g., mental health problems, substance misuse), and no homeless-specific measurement instruments have been validated (Kryda and Compton, 2009; Olivet et al., 2010; Fazel et al., 2014; Sappok et al., 2015). To address some of these challenges we collected data using a keyworker interview, which we call the 'DSM-5 Autistic Traits in the Homeless Interview' (DATHI). We chose to use an interview, rather than a questionnaire or direct observation tool, to allow for in-depth consideration of whether particular behaviours are indicative of autism. For example, the back-and-forth discussion between interviewer and interviewee can help both parties reach a decision about whether an individual's lack of eye contact is pervasive across situations, or only occurs when that person is under the influence of substances. Our adoption of a keyworker interview also allowed us to screen an entire caseload of homeless people in one service, thus minimising sampling bias and increasing the generalizability of our findings. This approach was made possible by the fact that in the service we based this study, it was the norm for keyworkers to have longstanding (mean=2.9 years) relationships with their homeless clients.

Given that is was designed for the current study, a crucial question is whether the DATHI is reliable and valid. To investigate reliability, we measured agreement between blinded raters on a subsample of interviews. This was a stringent test of inter-rater reliability as we deliberately over-sampled 'marginal' cases. For all but one of the DATHI's items (each of which corresponds to a DSM-5 criterion for autism), inter-rater agreement was 'substantial', with the other item (A1 - 'social-emotional reciprocity') showing a 'moderate' level of agreement. Further, when we considered the instrument's ability to distinguish between those who screened positive for autism and those who did not, inter-rater agreement was 'substantial' (Kappa=.69). These findings suggest that the DATHI has adequate reliability. 
Autism (2018)

The case for the DATHI's content validity is supported by the fact that it was closely based on DSM-5 diagnostic criteria for autism spectrum disorder. Its face validity was checked by receiving comments on drafts from homelessness and autism experts, and by piloting the interview with keyworkers. We have included a copy of the DATHI in supplementary materials for this paper, and also present examples of behaviours coded in this study in Table 4, to allow readers to make up their own minds about content and face validity.

Initial evidence for criterion validity comes from the high levels of association with another professional-report measure of autism traits, the ASDASQ (Nylander \& Gillberg, 2001). We acknowledge that this is not an especially strong test of criterion validity, as the ASDASQ is a screening measure, and was designed for psychiatric populations, not homeless people. However, as our aim was to begin to develop an evidence base in this area we considered that results from the ASDASQ would at least provide some information regarding the criterion validity of the DATHI.

One challenge to the DATHI, and any assessment of autism in homeless people, is the high level of mental health difficulties and substance abuse problems in this population. The risk is that behaviours, such as social withdrawal or atypical non-verbal behaviour, could be mistakenly labelled as autistic in nature, when really they reflect a mental health problem or the effects of substance misuse. Therefore it is reassuring that in this study higher DATHI scores were not associated with higher rates of diagnosed mental health problems. Also there was an inverse relationship between reported substance abuse and autistic traits. These findings support the construct validity of the DATHI. Also, our prediction that homeless people with higher DATHI scores would be especially socially isolated was supported by the data, and this provides further evidence for the interview's construct validity (Howlin \& Moss, 2012). 
Autism (2018)

\section{Autistic traits and homelessness people}

Given the above initial evidence that the DATHI is an adequate keyworker-report measure of autistic symptoms in the homeless, our findings that autistic difficulties are over represented amongst homeless adults should be taken seriously. We believe they raise the following possibilities that are worthy of future investigation. First, autism is likely a risk factor for becoming homeless. Our findings hint at one mechanism that could underpin this, since we found that those homeless with autistic traits were more socially isolated. Perhaps a lack of social capital makes people more vulnerable to becoming homeless in the face of other risk factors such as poverty and unemployment (e.g., Calsyn \& Winter, 2002). Second, autistic homeless people may have a distinct profile of needs that impact on their daily life and chances of exiting homelessness. For example, sensory difficulties could make it hard for someone to live in a noisy hostel; and executive problems could make a transition to independent accommodation especially difficult.

\section{Limitations}

We have already discussed at length the challenges of assessing autism in homeless people and acknowledged that our findings are preliminary. Further validation of the DATHI will be valuable so that the instrument can be used in future investigations of autism and homelessness. This should involve testing the DATHI in the homeless population against the criterion of clinically diagnosed autism, based on a multi-disciplinary assessment (NICE, 2012). Such work will lay the ground for a more precise estimate of the true prevalence of autism amongst homeless people, and for studies that seek to identify the characteristics and needs of autistic homeless people.

There was a sizeable group of homeless people in this study who were so poorly known to services that no data could be gathered about the presence of ASC symptoms. They received the 
Autism (2018)

classification 'insufficient information to classify'. These individuals in general actively avoided contact with keyworkers, and while this could have a wide variety of causes it seems plausible that this would be the type of behaviour an autistic person might display. This may mean that our estimate of prevalence is too low.

With regards to the generalisability of our findings, we avoided sampling bias with respect to our target population, which was all the UK and Republic of Ireland-born clients of a specific English homelessness service. Nevertheless, this target population is not perfectly representative of the general homeless population, since they come from a service for the longterm homeless, who tend to have more complex presentations (Fazel et al., 2014). Future work should investigate autism in more diverse homeless populations.

\section{Clinical implications and future directions}

This study has provided initial evidence that rates autistic traits are raised in homeless populations. While this cannot be more than a tentative conclusion, this would be consistent with the well-evidenced poor outcomes for adults with ASC (Howlin and Moss, 2012; Steinhausen et al., 2016). Lai and Baron-Cohen (2015) refer to a 'lost generation' of adults with ASC who did not receive a diagnosis because of lack of knowledge about the condition, and the individuals we have identified may be part of this group.

If autistic difficulties are common among homeless populations this has important implications. Many people are homeless in the UK; the most recent estimate is that there are almost 5000 rough sleepers at any one point (Ministry of Housing, Communities and Local Government, 2017), and there is a much larger group of people with no stable accommodation who are termed the 'hidden homeless' (Crisis, 2017). There may therefore be a considerable number of 
Autism (2018)

homeless autistic adults who are not having their needs met, and who are in an extremely vulnerable position.

Some organisations have recently developed ways of supporting homeless autistic adults, and they have provided anecdotal evidence of success (e.g., Homeless Link, 2015). These interventions have used expertise from the autism field to inform keyworking, and relatively straightforward adaptations have reportedly allowed the engagement of adults who had previously refused support. It will be valuable to manualise and empirically test such interventions, to begin to build an evidence base for supporting autistic homeless people. Also, it will be important to research pathways into homelessness for autistic people, to understand the mechanisms of risk. This can then be used to design preventative strategies to help autistic adults avoid homelessness.

\section{ACKNOWLEDGEMENTS}

The authors wish to thank all the workers at the homeless service in which this project was based for their support and enthusiasm, and for being so generous with their time and expertise.

FUNDING

This work was partly supported by studentships to Alasdair Churchard and Morag Ryder from Health Education England. 
Autism (2018)

SUPPLEMENTARY MATERIALS AND ACCESSING RESEARCH MATERIALS

The main interview (the DATHI) used in this research has been uploaded in supplementary materials. Other questionnaires used and data relating to the study can be accessed by contacting Alasdair Churchard. 
Autism (2018)

\section{REFERENCES}

Barker, C., \& Pistrang, N. (2015). Research methods in clinical psychology: An introduction for students and practitioners. London: John Wiley \& Sons.

Brugha, T. S., Spiers, N., Bankart, J., Cooper, S.-A., McManus, S., Scott, F. J., ... Tyrer, F. (2016). Epidemiology of autism in adults across age groups and ability levels. The British Journal of Psychiatry : The Journal of Mental Science, 209(6), 498-503.

Butwicka, A., Långström, N., Larsson, H., Lundström, S., Serlachius, E., Almqvist, C., ... Lichtenstein, P. (2017). Increased risk for substance use-related problems in autism spectrum disorders: a population-based cohort study. Journal of autism and developmental disorders, 47(1), 80-89.

Calsyn, R. J., \& Winter, J. P. (2002). Social support, psychiatric symptoms, and housing: A causal analysis. Journal of Community Psychology, 30(3), 247-259.

Centers for Disease Control and Prevention. (2014). Prevalence of autism spectrum disorder among children aged 8 years - autism and developmental disabilities monitoring network, 11 sites, United States, 2010. Morbidity and Mortality Weekly Report: Surveillance Summaries, 63(2), 1-21.

Crisis. (2017). The homelessness monitor: England 2017. London: Author

Ministry of Housing, Communities \& Local Government. (2017). Rough Sleeping Statistics Autumn 2017, England. London: Author. 
Autism (2018)

Elo, S., \& Kyngäs, H. (2008). The qualitative content analysis process. Journal of advanced nursing, 62(1), 107-115.

Evans, R. (2011). The life we choose: Shaping autism services in Wales. Cardiff: National Autistic Society.

Fazel, S., Geddes, J. R., \& Kushel, M. (2014). The health of homeless people in high-income countries: Descriptive epidemiology, health consequences, and clinical and policy recommendations. The Lancet, 384(9953), 1529-1540.

Fazel, S., Khosla, V., Doll, H., \& Geddes, J. (2008). The Prevalence of Mental Disorders among the Homeless in Western Countries: Systematic Review and Meta-Regression Analysis. PLoS Med, 5(12), e225.

Fitzpatrick, S., Johnsen, S., \& Bramley, G. (2012). Multiple Exclusion Homelessness amongst Migrants in the UK. European Journal of Homelessness, 6(1), 31-58.

Fleiss, J. L., \& Cohen, J. (1973). The Equivalence of Weighted Kappa and the Intraclass Correlation Coefficient as Measures of Reliability. Educational and Psychological Measurement, 33(3), 613-619.

Fraser, R., Cotton, S., Gentle, E., Angus, B., Allott, K., \& Thompson, A. (2012). Non-expert clinicians' detection of autistic traits among attenders of a youth mental health service. Early Intervention in Psychiatry, 6(1), 83-86.

Gray, K. M., Keating, C. M., Taffe, J. R., Brereton, A. V., Einfeld, S. L., Reardon, T. C., \& Tonge, B. J. (2014). Adult Outcomes in Autism: Community Inclusion and Living Skills. Journal of Autism and Developmental Disorders, 44(12), 3006-3015. 
Autism (2018)

Homeless Link. (2015). Autism and Homelessness: Briefing for frontline staff. London: Author.

Howlin, P., Goode, S., Hutton, J., \& Rutter, M. (2009). Savant skills in autism: psychometric approaches and parental reports. Philosophical Transactions of the Royal Society B: Biological Sciences, 364(1522), 1359-1367.

Howlin, P., \& Moss, P. (2012). Adults with autism spectrum disorders. Canadian Journal of Psychiatry, 57(5), 275-283.

IBM SPSS. (2015). Stats Fleiss Kappa. IBM developerWorks.

Joshi, G., Wozniak, J., Petty, C., Martelon, M. K., Fried, R., Bolfek, A., ... Biederman, J. (2013). Psychiatric comorbidity and functioning in a clinically referred population of adults with autism spectrum disorders: A comparative study. Journal of Autism and Developmental Disorders, 43(6), 1314-1325.

Kryda, A. D., \& Compton, M. T. (2009). Mistrust of outreach workers and lack of confidence in available services among individuals who are chronically street homeless. Community Mental Health Journal, 45(2), 144-150.

Lai, M. C., \& Baron-Cohen, S. (2015). Identifying the lost generation of adults with autism spectrum conditions. The Lancet Psychiatry, 2(11), 1013-1027.

Landis, J. R., \& Koch, G. G. (1977). The measurement of observer agreement for categorical data. Biometrics, 33(1), 159-174. 
Autism (2018)

Loomes, R., Hull, L., \& Mandy, W. P. L. (2017). What is the male-to-female ratio in autism spectrum disorder? A systematic review and meta-analysis. Journal of the American Academy of Child \& Adolescent Psychiatry, 56(6), 466-474.

Magiati, I., Tay, X. W., \& Howlin, P. (2014). Cognitive, language, social and behavioural outcomes in adults with autism spectrum disorders: a systematic review of longitudinal follow-up studies in adulthood. Clinical Psychology Review, 34(1), 73-86.

Meilleur, A. A. S., Jelenic, P., \& Mottron, L. (2015). Prevalence of clinically and empirically defined talents and strengths in autism. Journal of autism and developmental disorders, 45(5), 1354-1367.

NHS Devon. (2011). Homelessness Health Needs Assessment. Exeter: Author.

NICE. (2012). Autism: recognition, referral, diagnosis and management of adults on the autism spectrum (CG142). Retrieved from: https://www.nice.org.uk/guidance/cg142 (accessed 14 June 2017).

Nylander, L., \& Gillberg, C. (2001). Screening for autism spectrum disorders in adult psychiatric out-patients: a preliminary report. Acta Psychiatrica Scandinavica, 103(6), 428-434.

Olivet, J., Bassuk, E., Elstad, E., Kenney, R., \& Jassil, L. (2010). Outreach and Engagement in Homeless Services: A Review of the Literature. The Open Health Services and Policy Journal, $3,53-70$.

Phillips, D. (2006). Moving Towards Integration: The Housing of Asylum Seekers and Refugees in Britain. Housing Studies, 21(4), 539-553. 
Autism (2018)

Robinson, E., St Pourcain, B., Anttila, V., Bulik-Sullivan, B., Kosmicki, J., Samocha, K., ... Borglum, A. (2017). Genetic risk for autism spectrum disorders and neuropsychiatric variation in the general population. European neuropsychopharmacology, (27), 279-280.

Roll, C. N., Toro, P. A., \& Ortola, G. L. (1999). Characteristics and experiences of homeless adults: A comparison of single men, single women, and women with children. Journal of Community Psychology, 27(2), 189-198.

Sappok, T., Heinrich, M., \& Underwood, L. (2015). Screening tools for autism spectrum disorders. Advances in Autism, 1(1), 12-29.

Schendel, D. E., Overgaard, M., Christensen, J., Hjort, L., Jørgensen, M., Vestergaard, M., \& Parner, E. T. (2016). Association of psychiatric and neurologic comorbidity with mortality among persons with autism spectrum disorder in a Danish population. JAMA pediatrics, $170(3), 243-250$.

Soulières, I., Dawson, M., Gernsbacher, M. A., \& Mottron, L. (2011). The level and nature of autistic intelligence II: what about Asperger syndrome?. PloS one, 6(9), e25372.

Steinhausen, H. C., Mohr Jensen, C., \& Lauritsen, M. B. (2016). A systematic review and metaanalysis of the long-term overall outcome of autism spectrum disorders in adolescence and adulthood. Acta Psychiatrica Scandinavica, 133(6), 445-452.

Streiner, D. L., Norman, G. R., \& Cairney, J. (2015). Health measurement scales: a practical guide to their development and use ( $5^{\text {th }}$ ed.). Oxford University Press, USA. 
Autism (2018)

van Heijst, B. F., \& Geurts, H. M. (2015). Quality of life in autism across the lifespan: A metaanalysis. Autism, 19(2), 158-167. 
Table 1 - Method for determining overall classification on the DSM-5 Autistic Traits in the Homeless Interview (DATHI)

\begin{tabular}{|l|l|}
\hline Classification & Scoring criteria \\
\hline Screened positive / present & $\begin{array}{l}\text { Section A: } 3 \text { items }=\text { present OR at least } 2 \text { items = present AND } 1 \text { item = possibly present } \\
\text { AND } \\
\text { Section B: At least } 2 \text { items = present OR } 1 \text { item = present AND at least } 2 \text { items = possibly present }\end{array}$ \\
\hline Screened marginal / possibly present & $\begin{array}{l}\text { Section A: At least } 3 \text { items = possibly present } \\
\text { AND } \\
\text { Section B: At least } 2 \text { items = possibly present }\end{array}$ \\
\hline Screened negative / not present & Does not meet criteria for 'Present' or 'Possibly present' \\
\hline $\begin{array}{l}\text { Screened negative / insufficient information to } \\
\text { classify }\end{array}$ & $\begin{array}{l}\text { Client is so poorly known to services that any attempt to match their behaviour to criteria would be a } \\
\text { guess (this same classification will be seen on individual items). }\end{array}$ \\
\hline
\end{tabular}


Table 2 - Item scores and Inter-rater reliability for the DSM-5 Autistic Traits in the Homeless Interview (DATHI)

\begin{tabular}{|c|c|c|c|c|c|c|c|}
\hline Criterion & $\begin{array}{c}\text { Average score } \\
\text { (SD) }\end{array}$ & \multicolumn{5}{|c|}{ Percentage of cases in each classification } & $\begin{array}{c}\text { Fleiss's kappa } \\
(95 \% \mathrm{Cl})\end{array}$ \\
\hline $\begin{array}{l}\text { A2: nonverbal } \\
\text { communication }\end{array}$ & $0.48(0.73)$ & 14.2 & 19.8 & 53.8 & 0.9 & 11.3 & $\begin{array}{c}0.65 \\
(0.44,0.87) \\
\end{array}$ \\
\hline A3: relationship & $0.58(0.79)$ & 18.9 & 19.8 & 48.1 & 0 & 13.2 & $\begin{array}{c}0.62 \\
(0.40,0.84)\end{array}$ \\
\hline B2: inflexibility & $0.39(0.68)$ & 11.3 & 16.0 & 57.5 & 1.9 & 13.2 & $\begin{array}{c}0.69 \\
(0.47,0.90)\end{array}$ \\
\hline B3: fixated interests & $0.29(0.65)$ & 10.4 & 8.5 & 67.9 & 1.9 & 11.3 & $\begin{array}{c}0.64 \\
(0.43,0.85)\end{array}$ \\
\hline B4: sensory differences & $0.25(0.59)$ & 7.5 & 10.4 & 69.8 & 0 & 12.3 & $\begin{array}{c}0.65 \\
(0.44,0.87)\end{array}$ \\
\hline
\end{tabular}

Note: Average score computed according to following procedure: items coded as 'Present' given a score of 2; coded 'Possibly present' given a score of 1; coded 'Not present', 'Present but attributable to cause other than autism', or 'Insufficient information to classify' given a score of 0. 
Table 3 - Examples of keyworkers' responses scoring as present on the DSM-5 Autistic Traits in the Homeless Interview (DATHI)

\begin{tabular}{|c|c|c|c|}
\hline \multirow{2}{*}{$\begin{array}{l}\text { Criterion } \\
\text { A1: Deficits in social-emotional } \\
\text { reciprocity }\end{array}$} & \multicolumn{3}{|c|}{ Examples of behaviours considered consistent with autistic traits } \\
\hline & $\begin{array}{l}\text { Many pauses in conversation, } \\
\text { would not say hello to someone } \\
\text { they do not know. }\end{array}$ & $\begin{array}{l}\text { Cannot say "how are you?" as finds } \\
\text { this insincere. One-sided } \\
\text { conversations and does not respond } \\
\text { to a smile. }\end{array}$ & $\begin{array}{l}\text { Does not initiate social interaction } \\
\text { and displays rigid smile when } \\
\text { greeted. Gives tangential responses } \\
\text { and speaks in stilted sentences. }\end{array}$ \\
\hline $\begin{array}{l}\text { A2: Deficits in nonverbal } \\
\text { communicative behaviors used for } \\
\text { social interaction }\end{array}$ & $\begin{array}{l}\text { Peculiar expression with eyes closed } \\
\text { and mouth open, displays what } \\
\text { appears to be a learnt smile. }\end{array}$ & $\begin{array}{l}\text { No eye contact, blank facial } \\
\text { expression, has to be told when } \\
\text { interactions are finished as would } \\
\text { not pick up on this otherwise. }\end{array}$ & $\begin{array}{l}\text { Difficult to tell how they are feeling } \\
\text { from their facial expression, does } \\
\text { not use or pick up on body } \\
\text { language. }\end{array}$ \\
\hline $\begin{array}{l}\text { A3: Deficits in developing, } \\
\text { maintaining, and understanding } \\
\text { relationships }\end{array}$ & $\begin{array}{l}\text { Acts the same in different contexts. } \\
\text { Difficulties in social interaction led } \\
\text { to leaving accommodation. }\end{array}$ & $\begin{array}{l}\text { No friendships or interest displayed } \\
\text { in making friends, acts the same to } \\
\text { everyone they meet. }\end{array}$ & $\begin{array}{l}\text { No interest shown in making } \\
\text { friends, small talk. Often rude and } \\
\text { aggressive in interactions. }\end{array}$ \\
\hline $\begin{array}{l}\text { B1: Stereotyped or repetitive motor } \\
\text { movements, use of objects, or } \\
\text { speech }\end{array}$ & $\begin{array}{l}\text { Plays with cuffs and rubs legs all the } \\
\text { time, moves papers repeatedly in } \\
\text { and out of envelope. Seems like } \\
\text { there is a rhythm to these } \\
\text { behaviours. }\end{array}$ & $\begin{array}{l}\text { Repeatedly moves arms in a very } \\
\text { particular way. Speaks in an old- } \\
\text { fashioned way, stereotyped old- } \\
\text { fashioned way of saying goodbye. }\end{array}$ & $\begin{array}{l}\text { Described as talking like a character } \\
\text { from a nineteenth century novel. } \\
\text { Consistently uses unusual name for } \\
\text { people in authority. }\end{array}$ \\
\hline $\begin{array}{l}\text { B2: Insistence on sameness, } \\
\text { inflexible adherence to routines, or } \\
\text { ritualized patterns of verbal or non- } \\
\text { verbal behavior }\end{array}$ & $\begin{array}{l}\text { Room precisely ordered with similar } \\
\text { items placed in rows, but extremely } \\
\text { dirty. }\end{array}$ & $\begin{array}{l}\text { Items organised in rows in room. } \\
\text { Day follows precise routine of when } \\
\text { they sleep, watch TV. Always take } \\
\text { same route to shop and has rules } \\
\text { about where shopping can be } \\
\text { placed in flat. }\end{array}$ & $\begin{array}{l}\text { Possessions organised very } \\
\text { precisely on shopping trolley, would } \\
\text { take this on same route each day. } \\
\text { When trolley was stolen was } \\
\text { devastated. }\end{array}$ \\
\hline $\begin{array}{l}\text { B3: Highly restricted, fixated } \\
\text { interests that are abnormal in } \\
\text { intensity or focus }\end{array}$ & $\begin{array}{l}\text { Talks a lot about food, very picky } \\
\text { about foods, when shopping will } \\
\text { stare at one product for a long time } \\
\text { reading all ingredients. }\end{array}$ & $\begin{array}{l}\text { Everything they buy has a particular } \\
\text { animal on it. Likes one colour a } \\
\text { great deal, painted their room an } \\
\text { intense shade of this colour. }\end{array}$ & $\begin{array}{l}\text { Makes lists of obscure musicians, } \\
\text { has a large collection of broken } \\
\text { electronics. }\end{array}$ \\
\hline B4: Hyper- or hyporeactivity to & When fire alarm went off & Sensitive to texture of clothing, & Oversensitive to sound and light, \\
\hline
\end{tabular}




\begin{tabular}{|l|l|l|l|}
\hline $\begin{array}{l}\text { sensory input or unusual interests } \\
\text { in sensory aspects of the } \\
\text { environment }\end{array}$ & $\begin{array}{l}\text { unexpectedly seemed like they } \\
\text { would scream, always has curtains } \\
\text { closed, burnt hand badly but } \\
\text { seemed under-reactive to pain } \\
\text { (waited one week to seek } \\
\text { treatment). }\end{array}$ & $\begin{array}{l}\text { checks before purchasing anything. } \\
\text { Attracted by flashing light. Has TV } \\
\text { on very loud, while in hospital } \\
\text { would have TV screen very close to } \\
\text { face. }\end{array}$ & $\begin{array}{l}\text { does not like TV being left on when } \\
\text { is in office with keyworker, refused } \\
\text { own TV. Complains about noises } \\
\text { others cannot hear. }\end{array}$ \\
\hline
\end{tabular}


Table 4 - Demographic details and length of homelessness by classification on DSM-5 Autistic Traits in the Homeless Interview (DATHI)

\begin{tabular}{|c|c|c|c|c|}
\hline \multirow[t]{2}{*}{ DATHI classification } & \multicolumn{2}{|c|}{ Gender } & \multirow[t]{2}{*}{ Mean age (SD) } & \multirow{2}{*}{$\begin{array}{c}\text { Mean length of } \\
\text { homelessness in years (SD) }\end{array}$} \\
\hline & Female & Male & & \\
\hline Screened positive / present & 2 & 11 & $53.5(14.6)$ & $11.8(10.9)$ \\
\hline Screened marginal / possibly present & 0 & 9 & $50.4(10.1)$ & $17.8(9.9)$ \\
\hline Screened negative / not present & 12 & 60 & $46.8(12.4)$ & $11.0(8.1)$ \\
\hline $\begin{array}{l}\text { Screened negative } \\
\text { / insufficient information to classify }\end{array}$ & 1 & 11 & $55.9(11.9)$ & $11.4(6.3)$ \\
\hline
\end{tabular}


Table 5 - Comparison of the characteristics of cases with and without elevated autistic traits on the DSM-5 Autistic Traits in the Homeless Interview (DATHI)

\begin{tabular}{|c|c|c|c|c|c|c|}
\hline & \multirow{2}{*}{$\begin{array}{c}\begin{array}{c}\text { No elevated } \\
\text { autistic traits }\end{array} \\
n=72\end{array}$} & \multirow{2}{*}{$\begin{array}{c}\text { Elevated autistic } \\
\text { traits } \\
n=22\end{array}$} & \multirow[t]{2}{*}{ Odds ratio } & \multirow[t]{2}{*}{ Significance } & \multicolumn{2}{|c|}{$95 \% \mathrm{Cl}$} \\
\hline & & & & & Lower bound & Upper bound \\
\hline \multicolumn{7}{|l|}{ Social network size } \\
\hline In a romantic relationship & 18 & 3 & 0.47 & 0.271 & 0.13 & 1.79 \\
\hline $\begin{array}{l}\text { Friends } \\
\end{array}$ & 57 & 11 & 0.26 & 0.010 & 0.10 & 0.72 \\
\hline Family & 37 & 4 & 0.21 & 0.010 & 0.06 & 0.68 \\
\hline Totally isolated & 11 & 10 & 4.62 & 0.005 & 1.61 & 13.29 \\
\hline Diagnosed mental health condition & 26 & 8 & 1.01 & 0.983 & 0.37 & 2.73 \\
\hline Drug and alcohol use & 56 & 12 & 2.92 & 0.037 & 1.07 & 7.98 \\
\hline
\end{tabular}

Note: Elevated autistic traits defined as 'screened positive' or 'marginal' on the DATHI 
Autism (2018)

Figure 1 - Screening, reliability checking, and classification process

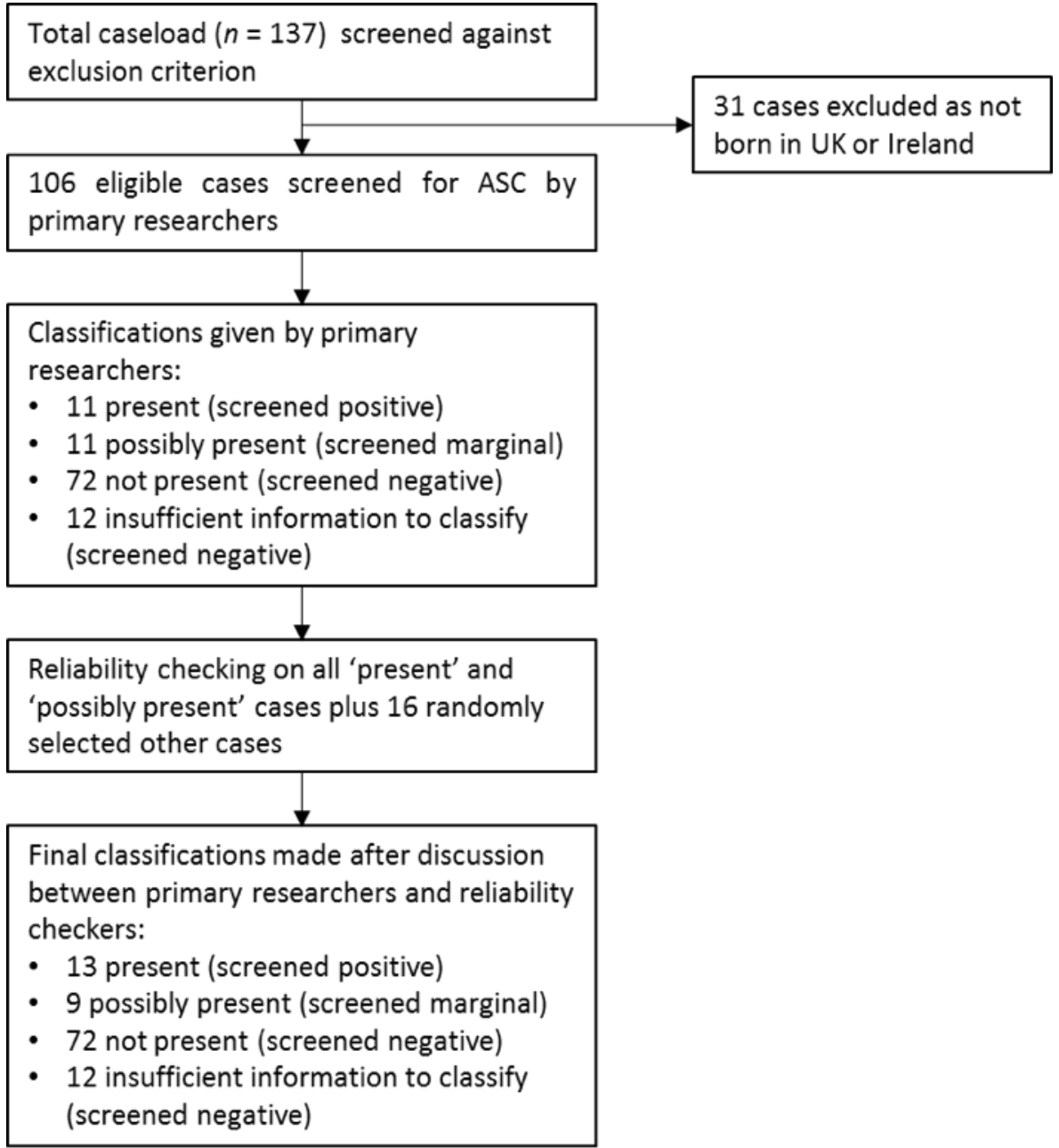

